\title{
Expressive differences for emotions in hearing impaired and with hearing individuals
}

Anjali Ghosh ${ }^{1}$

${ }^{1}$ Psychology Research Unit, Indian Statistical Institute, India

\begin{abstract}
Emotion is the most common experience of all human beings, whether normal or impaired. The universal emotions like happiness, sadness, anger, fear etc. are well recognizable through facial expressions. But even though we may identify these emotions clearly, we display them differently towards different target persons. The objective of the present study is two-fold: (1) to understand the pattern of display rules of four emotions namely, happiness, anger, fear and sadness in hearing impaired and with hearing individuals in private and public contexts, and (2) to find out whether display rules of emotions are equal for all target persons i.e. parents, friends and teachers. Display Rule Assessment Inventory of Matsumoto et al. (2005) was administered to 204 hearing-impaired and 273 with hearing individuals. The findings of the study indicate that the pattern of overall expression of emotions are different for hearing-impaired and for hearing individuals. Repeated Measure ANOVA results indicate a significant main effect of context on overall expression of both positive and negative emotions. The results also show that emotions are displayed in an amplified manner depending upon the target person. On the whole, the findings indicate that both hearing and impaired individuals regulate positive and negative emotions depending upon the target person and context.
\end{abstract}

\section{Keywords: Emotions; Hearing Impaired; Target person; Context.}

Diferenças na expressão emocional entre indivíduos portadores e não-portadores de deficiências auditivas: A emoção é uma das experiências mais comuns do ser humano, quer este seja, ou não, portador de deficiência. As emoções universais tais como a felicidade, tristeza, fúria ou medo, etc., são bem reconhecidas através de expressões faciais. No entanto, e ainda que se consiga identificar de forma clara estas emoções, a expressão individual das mesmas pode ser diferente consoante a pessoa a quem as dirigimos. 0 objectivo do presente estudo é duplo: (1) compreender o padrão de expressão de quatro emoções, designadamente felicidade, fúria, medo e tristeza, junto de indivíduos portadores de deficiência auditiva e indivíduos não-portadores, em contextos públicos e privados; e (2) compreender se a expressão destas emoções é igual para todos os tipos de pessoas-alvo, ou seja, pais, amigos e professores. 204 indivíduos portadores de deficiências auditivas e 273 indivíduos não-portadores preencheram o Display Rule Assessment Inventory de Matsumoto et al. (2005). Os resultados mostram que o padrão geral de expressão de emoções é muito diferente para indivíduos portadores de deficiência auditiva quando comparado com indivíduos não-portadores. Os resultados de uma ANOVA de medidas repetidas evidenciaram um efeito principal do contexto na expressão geral de emoções positivas e negativas. Os resultados mostram, também, que as emoções são expressadas de forma amplificada dependendo da pessoa-alvo. De uma forma global, estes resultados indicam que tanto indivíduos não-portadores, como indivíduos portadores de deficiência auditiva, regulam a expressão de emoções positivas e negativas, dependendo do alvo e do contexto.

Palavras-chave: Emoções; Deficiência Auditiva; Pessoa-alvo; Context.

Emotion is a complex psychological state that involves three distinct components: a subjective experience, a physiological response, and a behavioral or expressive response (Hockenbury \& Hockenbury, 2007. pp. 117). This is applicable for both positive and negative emotions. The universal basis of seven emotions namely, anger, contempt, disgust, fear, happiness, sadness and surprise are well recognizable through facial expressions (Ekman, 1999; Ekman \& Rosenberg, 1998). Emotion is associated with mood, temperament, personality, disposition, and motivation. The existence of display rules were originally documented in Ekman's (1972) classic study of Americans and Japanese students viewing stressful films when alone and subsequently with an experimenter. The expression of emotion is likely to vary depending on social expectations in specific social environments, which is called the "emotional display

${ }^{1}$ Address for correspondence: Anjali Ghosh, Psychology Research Unit, Indian Statistical Institute, 203,B.T. Road, Kolkata -700108 India. Email: gh.anjali@gmail.com. 
rules" (Hou \& Yu, 2006). Ekman (1972 pp. 207-283) defines emotional display rules (EDR) as what has been learned, presumably fairly early in life, about which emotion management techniques are to be applied by whom, to which emotions, under what circumstances. The social situations may vary for friends, family members and acquaintances as well as for persons with higher and lower social status. These culturally shared norms dictate how and when to apply this. Display rules are culturally informed guides about what type of facial expressions and other emotional displays for a certain emotion are allowed, suppressed, or exaggerated in a given situation (Colman, 2001; Denham \& Mitchell-Copeland, 1993; Ekman \& Friesen, 1969; Matsumoto, Yoo, Hirayama, \& Petrova, 2005). Individuals are socialized to know and enact display rules for different emotions in different situations (Denham, McKinley, Couchoud, \& Holt, 1990; Garner, Jones, \& Minner, 1994), so that they may become socially appropriate to interact in a given culture. Display rules are thus conceptualized as a mechanism that explains emotion expression management (Matsumoto et al., 2005). Matsumoto (1990) rated emotional facial expressions to determine how appropriate the expression of the specific emotion is for different target persons and to who people should express their emotional experiences.

Literature indicated that there is a good relationship between individuals' ability to apply EDR and social abilities (Jones, Abbey, \& Cumber 1998; McDowell \& Parke, 2000). Underwood (1992) found that compared to non-aggressive individuals, aggressive individuals used less EDR to disguise their anger. Matsumoto (1990) refers to display rules as values concerning the appropriateness of emotional displays that are communicated from one generation to the next. Studies reported that children understand verbal display rules better than facial display rules, and they understand prosocial display rules better than selfprotective ones. Matsumoto et al. (2008) investigated collective effects of display rules across 32 countries and found greater expression toward in-groups than out-groups and an overall regulation effect.

Individuals with any kind of impairment (visual, hearing, mental etc.) experience challenges not only in their physical capacity, but also challenges in their psychological capacities to adjust with their disabilities. Visual impairment (including blindness) means impairment in vision that even with correction, adversely affects a child's educational performance. Hearing impairment, on the other hand, is a broad term that refers to hearing losses of varying degrees from hard-of hearing to total deafness. One particular area of challenge for the hearing impaired children is the ability to socialize as because they cannot communicate. Hearing impaired children have difficulties in acknowledging that different people can hold different mental states regarding the same situation (Peterson \& Siegal, 2000). The consequences of these difficulties can be inferred from their problems in relationships with peers. An important aspect of regulating relationships with others is the use of emotions. It has been observed that in course of development, children learn to display their emotions depending upon the social circumstances and in accordance with the cultural norms (Malatesta \& Haviland, 1982). Hearing impaired children have been found to mask their emotions particularly anger and happiness, less frequently than normal hearing children (Hosie et al., 2000). Moreover, Hosie and colleagues (2000) found that hearing impaired children's reasons for masking their true feelings were comparatively less protective and they gave more reasons that were pro-social or concerned with norm maintenance. Rieffe \& Terwogt (2006) observed that in conflict situations, deaf children used anger expression more bluntly towards peers than hearing children, and their findings suggest that emotional coaching with families and the school curriculum seem essential for developing the socio emotional competence of deaf children. Gray, Hosie, Russel \& Ormel (2001) and Dyck, Farrugia, Shochet \& Holmes-Brown (2004) studied participants identifying universal facial expression of emotions from a broad range of spectrum of deaf children in and observed lower performance of deaf children in identifying and labeling emotions compared to their hearing peers.

Considering these issues, the present investigation tries to understand the pattern of emotional display rules for anger, happiness, sadness and fear in hearing impaired and normal hearing adolescents in two different situations (private and public) towards in-group and out-group members. Parents and friends are considered as in-group members whereas teachers as out-group members. These positive and negative emotions have been selected for the study as we experience these emotions frequently in our daily lives. Happiness is a positive emotion and we feel it whenever we are satisfied, feel pleasure, joy or contentment. Anger occurs when we believe that we have been or are threatened with being deprived of something we believe is rightfully ours. Sadness, on the other hand, is a negative emotion and we feel it when we experience loss of someone or experience a helpless situation. Fear is also a negative emotion which creates anxiety and agitation in one's mind by the presence or nearness of danger or pain. The objective of the present study is to address the following two issues:

(a) To understand the pattern of display rules of four emotions namely, happiness, sadness, anger and fear in hearing impaired and with hearing adolescents across private and public contexts. 
(b) To find out whether emotional display rules of these two groups are equal for all target persons i.e. parents, friends (in-group member) and teachers (out-group member).

\section{METHOD}

\section{Participants}

Participants of this study were 477 school students (204 hearing impaired and 273 with hearing) belonging to different states of India. There were 204 hearing impaired (Male $=139$, Female $=65$ ) and 273 with hearing (Male $=122$, Female $=151$ ) individuals in this study. The mean age of the hearing impaired students was 16.33 years $(S D=2.30)$ and for with hearing students it was 15.37 years $(\mathrm{SD}=1.25)$. The majority of the hearing impaired students were day scholars and residing with their parents/guardians or otherwise in the hostel, but all the normal hearing students were day scholars and residing with their parents/guardians. The socio-economic condition of the students varied from lower middle to upper middle class.

\section{Measures}

\section{Display Rule Assessment Inventory}

The Display Rule Assessment Inventory developed by Matsumoto, Yoo, Hirayama and Petrova (2005) was used in this study. The inventory measures display rules across a wide range of target persons such as family members, friends, acquaintances and teachers/ professors. Seven universally expressed emotions namely anger, contempt, disgust, fear, happiness, sadness and surprise are used in the inventory. But in the present investigation only four emotions namely, happiness (positive emotion), and sadness, anger and fear (negative emotions) were used. Participants were asked to mention their expressive behavior towards three target persons namely, parents and friends (i.e. in-group member), and teacher (i.e., outgroup member). They were asked to express "what they should do if they felt" these four emotions toward these target persons under two different settings/contexts (a) in private context (i.e., "at home or in the classroom with the target person alone") and (b) in public context (i.e., "at restaurant or in the classroom with the target person within earshot of others"). The response alternatives correspond to the theoretical modes of expression management originally described by Ekman \& Freisen $(1969,1975)$, which are: (a) show more than you feel it (amplify), (b) express it as you feel it (express), (c) show less than you feel it (deamplify), (e) show the emotion while smiling at the same time (qualify), (f) hide your feelings by smiling (masking), and (g) show nothing (neutralize).

\section{Background Information Schedule}

Background information were also collected from the participants through a schedule which included items like participants' age, gender, disability status, family structure, educational level, socio-economic condition of the family etc.

\section{Procedure}

Informed consent was given by the hearing impaired and hearing participants of the selected schools. Hearing impaired participants were either interviewed individually or tested in group situation in the classroom with the help of their teachers through sign language and all the normal hearing individuals were tested in the classroom of their respective schools in group situation. The language of instruction and administration of the tests for with hearing children were either English or Hindi or Bengali depending upon the languages known by the participants. All of them were asked to imagine how they would express these four emotions namely, happiness, sadness, anger and fear in a hypothetical situation through their behavior in terms of six response formats (which were presented through sentences) toward in-group member (i.e., parents and friends) and out-group member (i.e., teachers) under two different situations (i.e., private and public). The response alternatives were as follows:

(A) Express: (express it as you feel it)

(B) Amplify: (show more than you feel it)

(C) Deamplify: (show less than you feel it)

(D) Neutralize: (show nothing)

(E) Qualify: (show the emotion while smiling at the time)

(F) Masking: (hide your feelings by smiling)

In this study we have used one positive and three negative emotions. It is because positive emotions are comparatively few and relatively difficult to differentiate. On the other hand, negative emotions are distinctly different experiences and have specific facial configurations. In the list of seven universal emotions of Ekman (1999), only happiness and surprise are positive emotions while the other five are negative emotions. It was envisaged that the 'surprise' emotion will be difficult to explain to the 
hearing-impaired group and therefore, only one positive emotion 'happiness' and three negative emotions 'anger', 'sadness' and 'fear' were used.

\section{RESULTS}

The scoring of DRAI is usually done through two procedures. In this study we have scored the data through procedure I. In procedure I overall expressivity score for emotions was calculated by following the scoring method suggested by Matsumoto et al. (2008) where the original nominal raw data were converted into continuous scales so as to maximize the use of inferential statistics. Homogeneity Analysis via Alternating Least Squares (HOMALS) analysis was used by Matsumoto et al. (2008) to arrive at one dimensional solution and which was found to be equivalent across cultures. The nominal expressive mode responses were recoded into the following scalar values for analysis, that is for amplify: .57; express: .38; qualify: .12; deamplify: -.15; masking: -.38; and neutralize: -.53. Matsumoto et al (2008) referred this dimension as a measure of overall expressivity. These scores were added by .5338 in each category to ease in the interpretation. The resulting scores ranged from " 0 " (hide your feelings by smiling) to "1.0989" (show more than you feel it).

In procedure II only ' 1 ' and ' 0 ' is used for scoring. Expression and Neutralization mode are calculated together, where expression mode is scored as either 1 or 0 , but Neutralization mode is scored as -1 and 0 . For the other four expressive modes only ' 1 ' and ' 0 ' are used.

Here we scored the data for computing the overall expressivity score for emotions by procedure I only, and then means and SD values for the two groups of individuals were calculated. The mean differences between the two contexts were also computed and the results are presented in Tables 1 and 2 .

Table 1. Mean, SD and values of difference (Diff.) between private and public contexts for the four emotions towards three target persons for Hearing-impaired individuals.

\begin{tabular}{|c|c|c|c|c|c|c|c|c|c|c|}
\hline \multirow{2}{*}{\multicolumn{2}{|c|}{ Emotion }} & & & \multicolumn{7}{|c|}{ Target person } \\
\hline & & \multicolumn{2}{|c|}{ Parents } & \multirow[b]{2}{*}{ Diff } & \multicolumn{2}{|c|}{ Friends } & \multicolumn{4}{|c|}{ Teacher } \\
\hline & & Private & Public & & Private & Public & Diff. & Private & Public & Diff. \\
\hline \multirow[t]{2}{*}{ Happiness } & $\mathbf{M}$ & .68 & .64 & .04 & .66 & .66 & .00 & .65 & .67 & -.02 \\
\hline & SD & .34 & .38 & & .36 & .39 & & .34 & .37 & \\
\hline \multirow[t]{2}{*}{ Sadness } & $\mathbf{M}$ & .61 & .57 & .04 & .62 & .48 & .14 & .54 & .51 & .03 \\
\hline & SD & .38 & .36 & & .39 & .38 & & .36 & .35 & \\
\hline \multirow[t]{2}{*}{ Anger } & $\mathbf{M}$ & .82 & .65 & .17 & .72 & .61 & .11 & .68 & .73 & .05 \\
\hline & SD & .34 & .37 & & .31 & .34 & & .36 & .35 & \\
\hline \multirow[t]{2}{*}{ Fear } & $\mathbf{M}$ & .53 & .55 & -.02 & .57 & .57 & .00 & .46 & .56 & -.10 \\
\hline & SD & .34 & .34 & & .33 & .33 & & .32 & .31 & \\
\hline
\end{tabular}

Note. Mean Difference (Diff.) was calculated as private minus public score.

Table 2. Mean, SD and difference values (Diff.) between private and public contexts for the four emotions towards three target persons for with Hearing individuals.

\begin{tabular}{|c|c|c|c|c|c|c|c|c|c|c|}
\hline \multirow{3}{*}{\multicolumn{2}{|c|}{ Emotion }} & & & \multicolumn{7}{|c|}{ Target person } \\
\hline & & \multicolumn{2}{|c|}{ Parents } & \multirow[b]{2}{*}{ Diff } & \multicolumn{2}{|c|}{ Friends } & \multicolumn{4}{|c|}{ Teacher } \\
\hline & & Private & Public & & Private & Public & Diff. & Private & Public & Diff. \\
\hline \multirow[t]{2}{*}{ Happiness } & $\mathbf{M}$ & .81 & .77 & .04 & .81 & .79 & .02 & .72 & .71 & .01 \\
\hline & SD & .35 & .32 & & .36 & .32 & & .36 & .36 & \\
\hline \multirow[t]{2}{*}{ Sadness } & $\mathbf{M}$ & .42 & .36 & .06 & .47 & .36 & .11 & .40 & .39 & .01 \\
\hline & SD & .38 & .34 & & .38 & .33 & & .34 & .35 & \\
\hline \multirow[t]{2}{*}{ Anger } & $\mathbf{M}$ & .71 & .54 & .17 & .70 & .52 & .18 & .50 & .47 & .03 \\
\hline & SD & .33 & .33 & & .35 & .36 & & .34 & .33 & \\
\hline \multirow[t]{2}{*}{ Fear } & $\mathbf{M}$ & .53 & .43 & .10 & .51 & .46 & .05 & .53 & .52 & .01 \\
\hline & SD & .35 & .32 & & .32 & .30 & & .33 & .34 & \\
\hline
\end{tabular}

Note. Mean Difference (Diff.) was calculated as private minus public score.

The overall expressivity score for emotions indicated that the positive emotion- happiness was expressed most in private situation by normal hearing adolescents towards all the target persons. But hearing impaired adolescents displayed anger more towards parents and teachers than the other emotions. Normal hearing students expressed negative emotions particularly anger less in public situation, but hearing impaired students expressed it more publicly towards teachers particularly "anger" 
and "fear". It may be due to the fact that these hearing impaired students spend more time with their teachers in schools and they do not mask their emotions much, particularly anger as the normal hearing children which corroborates the findings of Hosie et al., (2000)., which indicate that hearing-impaired children hide or mask their emotions less frequently. The hearing-impaired children due to their inability of communication or language expression, do not hide their emotions particularly anger. For normal hearing children, it may be that showing anger more in front of others is not a good sign of behavior in Indian culture. In case of students the restriction is more, so they prefer to express this emotion more in private contexts.

It has been observed that normal hearing individuals show both positive and negative emotions less in public context whereas hearing-impaired individuals show happiness, anger and fear more in public context specially towards out-group member i.e. teacher.

The mean difference between the contexts is higher for negative emotions particularly for anger for the in-group members in both hearing impaired and normal hearing individuals. That is they show more negative emotion in private context. But hearing-impaired individuals expressed anger more publicly towards teachers.

The overall expressivity score for emotions varied from target person to target person and also from context to context for both the groups. Repeated Measure ANOVA was calculated to see whether the emotional display of these subjects varied due to target person and/or context. This was done separately for the four emotions. The main effect of target person: $F(2,472)=4.56, p<.01$ and context $F(1,473)=$ $3.23, p<.07$ was found to be significant for the emotion happiness. The interaction effect of target $\times$ status of the group: $F(2,472)=5.79, p<.003$, target $\mathrm{x}$ context $\times$ gender: $F(2,472)=4.14, p<.02$ were found to be significant for overall expression of happiness. The results show that the emotion happiness displayed by hearing impaired and with hearing adolescents varied for different target persons and also under private and public contexts.

The results indicate significant main effect of target person: $F(2,472)=18.84, p<.000$ and context $F(1,473)=63.62, p<.000$ on overall expression of anger which reveal that anger expression varied from target person to target person and also from private to public context. These main effects were qualified by a significant interaction effect of target $\times$ status: $F(2,472)=12.85, p<.000$ and also by a significant interaction effect of target $\mathrm{x}$ gender $F(2,472)=6.02, p<.003$. The main effects were also qualified by a significant interaction effect of target $\times$ status $\times$ gender: $F(2,472)=4.99, p<.007$. There are also significant interaction effects of context $\mathrm{x}$ status $F(1,473)=4.95, p<.03$ and target $\times$ context: $F(2,472)=$ 25.26, $p<.000$.This results indicate that both status of the group (hearing impaired and normal hearing) and gender (male and female) display anger differently towards parents, friends and teachers in private and public contexts.

The negative emotion sadness was also found to have asignificant main effect of context, $F(1,473)=$ 24.72, $p<.000$. This main effect was qualified by a significant interaction effect of context $\mathrm{x}$ gender: $F(1,473)=9.77, p<.00$, context $\mathrm{x}$ status $\mathrm{x}$ gender: $F(1,473)=11.36, p<.000$ and target $\mathrm{x}$ context: $F(2,472)$ $=7.34, p<.03$. This shows that both hearing-impaired and with hearing individuals show sadness differently in private and public situation and that too is qualified by one's gender.

Fear is also a negative emotion, but it was found to have significant interaction effect. Target $\mathrm{x}$ status of the group interacted significantly $F(2,47)=5.75, p<.00$, and also context $\mathrm{x}$ status of the group $F(1,473)=12.50, p<.000$. Target $\mathrm{x}$ context was also found to have a significant interaction effect: $F(2,472)=7.34, p<.000$. Gender was not found to have any significant effect.

\section{DISCUSSION}

Emotional display rules of hearing impaired and with hearing students towards three target persons was studied under private and public contexts. The overall findings indicate that these emotions are displayed differently towards three target persons in different situations but the overall expressivity for emotions is slightly different for the hearing-impaired and with hearing groups. The study reflects more emphasis on positive emotion (happiness) than negative emotion (anger) by the normal hearing individuals. But the hearing-impaired group emphasized negative emotion particularly, anger more than the positive emotion. Display of emotion was more evident in relation to positive emotion and that too in private situations, which suggests that Indians, particularly the normal hearing group of individuals do not want to display emotions more in public situation especially for the negative emotions.

The magnitude for overall expression of difference between the two contexts was found to be more for negative emotion than positive emotion and this is mainly for in-group members. The probable reason may be that in Indian culture to express negative emotion in front of outsiders (i.e., publicly) is not a good sign of behaviour. The restriction is even more in case of students, so they prefer to hide or mask or suppress it publicly. But for the hearing-impaired group it was not the case. They displayed negative 
emotion more for the out-group member, which may be due to the fact that they spent more time with their teachers and they do not hide or mask the emotion like the normal hearing group.

The present study highlighted the display of positive and negative emotions of one differently abled (hearing impaired) and one normal hearing group of students. Self - report of the emotions through written sentences toward different target persons is definitely a limitation of the study as it did not actually measure the expression of emotions. But still this gives an indication of the display rules followed by normal hearing and hearing-impaired groups. The study implies that overall expression and regulation of emotions is an important issue for maintaining good social relationships with others for the impaired groups as well as the normal hearing individuals depending upon the target person and the context. Future studies may be done with other indicators which will develop our findings.

\section{References}

Colman, A. M. (2001). Dictionary of psychology (1st ed.). New York: Oxford University Press.

Denham, S. A., McKinley, M., Couchoud, E. A., \& Holt, R. (1990). Emotion and behaviour predictors of preschool peer ratings. Child Development, 61, 1145-1152. http://dx.doi.org/10.2307/1130882

Denham, S. A., \& Mitchell-Copeland, J. (1993). Cross-validation of Lewis \& Michaelson's system for measurement of children's emotional states. Infant Mental Health Journal, 14, 133-146. http://dx.doi.org/10.1002/1097-0355(199322)14:2<133::AID-IMHJ2280140207>3.0.CO;2-V

Dyck, M. J., Farrugia, C., Shochet, I.M., \& Holmes-Brown, M (2004). Emotion recognition understanding ability in hearing or vision impaired children: Do sounds, sights or words make the difference? Journal of Child Psychology and Psychiatry, 45, 789-800. http://dx.doi.org/10.1111/j.1469-7610.2004.00272

Ekman, P. (1972). Universals and cultural differences in facial expression of emotion. In J. R. Cole (Ed.), Nebraska symposium on motivation (pp. 207-283). Lincoln, NE: University of Nebraska Press.

Ekman, P. (1999). Basic emotions. In T. D. A. T. Power (Ed.), The handbook of cognition and emotion (pp. 45-60). United Kingdom: John Wiley and Sons Ltd.

Ekman, P., \& Friesen, W. V. (1969). The repertoire of nonverbal behavior: Categories, origins, usage, and coding. Semiotica, 1, 49-98.

Ekman, P., \& Rosenberg, E. L. (Eds.) (1998). What the face reveals: Basic and applied studies of spontaneous expression using the Facial Action Coding System (FACS). New York, NY: Oxford University Press.

Garner, P. W., Jones, D. C., \& Minner, J. L. (1994). Social competence among low-income preschoolers: Emotion socialization practices and social cognitive correlates. Child Development, 65, 622-637. http://dx.doi.org/10.2307/1131405

Gray, C. D., Hosie, J. A., Russell, P. A., \& Ormel, E. A (2001). Emotional development in deaf children: Facial expressions, display rules, and theory of mind. In M. D. Clark, M. Marschark, \& M. Karchmer (Eds.), Context, cognition and deafness (pp. 135-157). Washington, DC: Gallaudet University Press.

Hockenbury, D. H., \& Hockenbury, S. E. (2007). Discovering psychology. New York: Worth Publishers.

Hosie, J. A., Russell, P. A., Gray, C. D., Scott, C., Hunter, N., Banks, J. S., et al. (2000). Knowledge of display rules in prelingually deaf and hearing children. Journal of Child Psychology \& Psychiatry \& Allied Disciplines, 41, 389-398. http://dx.doi.org/10.1111/1469-7610.00623

Hou, R. H., \& Yu, G. L. (2006). Children's understanding of emotional display rules and use of strategies. Psychological Science (in Chinese), 29, 18-21.

Jones, D. C., Abbey, B. B., \& Cumberland, A. (1998). The development of display rule knowledge: Linkages with family expressiveness and social competence. Child Development, 69, 1209-1222. http://dx.doi.org/10.2307/1132370

Malatesta, C. Z., \& Haviland, J. M. (1982). Learning display rules: The socialization of emotion expression in infancy. Child Development, 33, 991-1003. http://dx.doi.org/10.2307/1129139

Matsumoto, D. (1990). Cultural similarities and differences in display rules. Motivation \& Emotion, 14, 195-214. http://dx.doi.org/10.1007/BF00995569

Matsumoto, D., Yoo, S. H., Fontaine, J. R. J., Angus-Wong, A. M., Arriola, H., Ataca, B., et al. (2008). Mapping expressive differences around the world: The relationship between emotional display rules and individualism versus collectivism. Journal of Cross-Cultural Psychology, 39, 55-74. http://dx.doi.org/10.1177/0022022107311854

Matsumoto, D., Yoo, S. H., Hirayama, S., \& Petrova, G. (2005). Development and initial validation of a measure of display rules: The Display Rule Assessment Inventory (DRAI). Emotion, 5, 23-40. http://dx.doi.org/10.1037/1528-3542.5.1.23

McDowell, D. J., \& Parke, R. D. (2000). Differential knowledge of display rules for positive and negative emotions: Influences from parents, influences on peers. Social Development, 9, 415-432. http://dx.doi.org/10.1111/1467-9507.00136 
Peterson, C. C., \& Siegal, M. (2000). Insights into theory of mind from deafness \& autism. Mind \& Language, 15, 123- 145. http://dx.doi.org/10.1111/1468-0017.00126

Rieffe, C., \& Terwogt, M. M. (2006). Anger communication in deaf children. Cognition and Emotion, 20(8), 1261-1273. http://dx.doi.org/10.1080/02699930500513502

Underwood, M. K., Coie, J. D., \& Herbsman, C. R. (1992). Display rules for anger and aggression in schoolage children. Child Development, 63, 366-380. http://dx.doi.org/10.2307/1131485

Historial do artigo

Recebido 25/02/2016

Aceite $\quad 30 / 10 / 2016$

Publicado 12/2016 
Expressive Differences for Emotions 